$\xi$

\title{
Band Gap Modification of Tio2 Using Solid State Reaction with Hydrides in Argon Atmosphere
}

\author{
Saad Sh. Al-Omary ${ }^{1}$, Laith A. Algharagholy ${ }^{2}$, Mohsin E. Al-Dokheily ${ }^{3}$ \\ ${ }^{1}$ Chemistry Department, College of Science, University of Dhi-Qar, Nasiriyah, Dhi-Qar, Iraq. \\ ${ }^{2}$ Department of Natural Science, College of Basic Education, University of Sumer, Refayee, Dhi-Qar, Iraq. \\ ${ }^{3}$ Chemistry Department, College of Science, University of Dhi-Qar, Al Islah, Dhi-Qar, Iraq. \\ Corresponding author: Saad Sh. Al-Omary \\ Nasiriyah, Dhi-Qar, Iraq \\ *Corresponding authorE-mail: saad.sh_chem@sci.utq.edu.iq
}

\begin{abstract}
$\mathrm{TiO}_{\mathrm{x}}(\mathrm{x}<2)$ nanoparticles have been synthesized by solid state reaction between as-prepared $\mathrm{TiO}_{2}$ nanoparticles and $\mathrm{NaAlH}_{4}, \mathrm{KBH}_{4}$ as a reducing agents in argon atmosphere at two temperature $600{ }^{\circ} \mathrm{C}$ and $850^{\circ} \mathrm{C}$. the X-ray diffraction patterns of reduced $\mathrm{TiO}_{2}$ shows a peak shift and broadening which attributed to the lattice contraction after reduction treatment. AFM images confirm that the surface roughness of reduced $\mathrm{TiO}_{2}$ were larger than unmodified $\mathrm{TiO}_{2}$ nanoparticles due to the formation of oxygen vacancies. UV-Vis spectroscopy measurements revealed that the reduced $\mathrm{TiO} 2$ nanoparticles have an absorption edge lies in the visible region from the electromagnetic radiations with lower band gap. EDS spectra indicate that the as-prepared and reduced $\mathrm{TiO}_{2}$ nanoparticles have a high degree of purity and the acquired results confirm formation nonstoichiometric $\left(\mathrm{TiO}_{2-\mathrm{x}}\right)$ with oxygen deficient.
\end{abstract}

Keywords: TiO2, band gap, reduction, solid state, DFT, SIESTA

\section{Introduction}

Titanium dioxide $\mathrm{TiO}_{2}$ has been studied intensively, this is because of its chemical and biological inertness, high photocatalytic efficiency, environmental tolerance, large stability, and low cost [1]. Many efforts have been made to modify $\mathrm{TiO}_{2}$ activity for degradation organic compounds, water splitting and for oxygen or hydrogen production $[2,3]$. Typically, the shape, size, crystal phase, crystallinity ,surface structure and defects represent the important parameters of $\mathrm{TiO}_{2}$, which are related strongly to its properties [4-8]. However, pure $\mathrm{TiO}_{2}$ is not a good material for practical applications because of the wide band gap (3.2 eV for anatase phase, and $3.0 \mathrm{eV}$ for rutile phase), this mean it can be activated only under the UV radiations which make about 5\% from the total solar radiation [9]. There are many treatments to improve the photocatalytictic activity of $\mathrm{TiO}_{2}$ in visible light range, this methods include doping titanium dioxide with metal ions such as $(\mathrm{Cu}, \mathrm{Fe}, \mathrm{V})$, and nonmetals such $(\mathrm{C}, \mathrm{N})$, and with rare earth elements and introducing defects into its structure [10].

Oxygen vacancy is one of the most important and is believed to be the common defect in many metal oxides, which has been investigated intensively by experimental characterizations and theoretical calculations.

Reduced $\mathrm{TiO}_{2}$ nanoparticles $\left(\mathrm{TiO}_{2-\mathrm{x}}\right)$, that contains oxygen vacancy or $\mathrm{Ti}^{+3}$ has been confirmed to show visible light absorption[11]. Yet it was thought that the introduced localized oxygen vacancy states that have energies of 0.75 to $1.18 \mathrm{eV}$ below the conduction band minimum of $\mathrm{TiO}_{2}$ nanoparticles are less than the redox potential for evolution of hydrogen, which, in combination with the little electron mobility in the bulk region related to this localization, makes the photocatalytic activity of the reduced $\mathrm{TiO}_{2}$ insignificant [12]. However, theoretical calculations estimate that a vacancy band of electronic states induced by high vacancy concentration can be a just below the conduction band[13]. However, these results show that it is possible to construct visible-light responsive $\mathrm{TiO}_{2}$ through introducing oxygen vacancy or $\mathrm{Ti}^{+3}[14]$.

Self-doping of $\mathrm{TiO}_{2}$ can be done using different reductants such as hydrogen gas, aluminium powder ,metallic zinc, sodium borohydride , diethylene glycol, carbon monoxide and so for.[15-20].

in this work, $\mathrm{TiO}_{2}$ nanoparticles was prepared using a well known sol-gel method, then, the band gap of as-prepared $\mathrm{TiO}_{2}$ nanoparticles were modified using solid state reaction method in inert atmosphere with new reductant materials. These modified $\mathrm{TiO}_{2}$ nanoparticles having lower band gap as compared with unmodified $\mathrm{TiO}_{2}$.

\section{Experimental}

\subsection{Materials}

The chemicals used in this work are (titanium tetraisopropoxide $97 \%$ , sodium aluminum hydride $90 \%$, Potassium borohydride 98\%) purchased from sigma Aldrich , (Isopropanol 90\%, Nitric acid 60\%) purchase from $\mathrm{BDH}$, the chemicals used in this work were of analytical reagent grade. 


\subsection{Preparation TiO2 nanoparticles}

Titanium dioxide nanoparticles were synthesized using sol-gel method, solution of titanium tetraisoprppoxide and isopropanol (5 $\mathrm{ml}$ isopropanol, $5 \mathrm{ml}$ titanium isopropoxide) was added gradualy to $200 \mathrm{ml}$ of deionzed water at $\mathrm{pH} 5$, the rate of addition is $2 \mathrm{ml} / \mathrm{min}$. When the addition is completed ,The mixture was kept 2 hours with continuous dynamic mixing at room temperature to reach the completion of hydrolysis. Then, the solution of transparent colloidal was left for 24 hours to complete aging, after that, filtered and dried for two hours at $90{ }^{\circ} \mathrm{C}$. For comparison, the resulted powder calcined for 4 hours in air atmosphere at $600{ }^{\circ} \mathrm{C}$, denoted $\mathrm{A}^{-\mathrm{TiO}_{2}}$ and at $850^{\circ} \mathrm{C}$, denoted $\mathrm{R}-\mathrm{TiO}_{2}$ to obtain anatase and rutile phase respectively.
Modified $\mathrm{TiO}_{2}$ was prepared using solid state reaction of uncalcined $\mathrm{TiO}_{2}$ with sodium aluminum hydride and potassium borohydride. 0.5 mole of $\mathrm{NaAlH}_{4}$ and $\mathrm{KBH}_{4}$ mixed with 1 mole of $\mathrm{TiO}_{2}$ separately. Mixed and grounded carefully and placed in quartz tube furnace and calcined in argon atmosphere at $600^{\circ} \mathrm{C}$ and $850{ }^{\circ} \mathrm{C}$, Finally, the products were allowed to cool at room temperature. To remove unreacted $\mathrm{NaAlH}$ and $\mathrm{KBH} 4$, the resulted powder washed with deionized water and ethanol several times. The resulted powder denoted T-Na-600, T-Na-850, T-K-600, T-K-850, where Na and K represent $\mathrm{NaAlH} 4$,KBH4 respectively , 600 and 850 represent calcinations temperatures. The conditions of solid state reactions experiments illustrated in table (1).

\subsection{Synthesis of modified $\mathrm{TiO} 2$ nanoparticles}

Table (1) solid state reaction conditions

\begin{tabular}{|l|l|l|l|}
\hline reactants & Mole ratio & Temperature ${ }^{\circ} \mathrm{C}$ & Reaction time \\
\hline $\mathrm{TiO}_{2}+\mathrm{NaAlH}_{4}$ & $1: 0.5$ & 600 & 1 hour \\
\hline $\mathrm{TiO}_{2}+\mathrm{NaAlH}_{4}$ & $1: 0.5$ & 850 & 1 hour \\
\hline $\mathrm{TiO}_{2}+\mathrm{KBH}_{4}$ & $1: 0.5$ & 600 & 1 hour \\
\hline $\mathrm{TiO} 2+\mathrm{KBH}_{4}$ & $1: 0.5$ & 850 & 1 hour \\
\hline
\end{tabular}

\subsection{Characterization}

$\mathrm{X}$-ray diffraction patterns of prepared and modified $\mathrm{TiO} 2$ were analyzed using Shimadzu X-Ray Diffractometer XRD 6000 with $\mathrm{Cu}$ $\mathrm{K} \alpha(\lambda=0.15405 \mathrm{~nm})$. Atomic force microscopy (AFM) images were measured using Advanced angstrom (AA3000) Model made in USA. Scanning electron microscopy (SEM) and energy dispersive spectroscopy (EDX) using Multi-Function Scanning Electron Microscope Model als 2300 Angstrom. The UV-Vis absorption spectra were recorded using Shimadzu UV-Visible 1800 spectrophotometer.

\section{Results and discussion}

The X-ray diffraction (XRD) is performed to identify the Changes of the crystalline phase of prepared and modified $\mathrm{TiO} 2$ nanoparticles. As shown in Figs. (1-2) and table(2), there were no other diffraction peaks, which indicated that the samples were pure, all the diffraction peaks related only to Tio2 Anatase (JCPDS Card No. 21-1272)and Rutile phases(JCPDS Card No. 21-1276). However, there is a significant peaks broadening and shifting in $2 \theta$ values to higher values after reduction reaction due to formation oxygen vacancies and lattice strains $(21,22)$. The crystallite size of prepared and modified Tio2 calculated using Scherrer equation(23):

$\mathrm{D}=0.9 \lambda / \beta \cos \theta$ where

$\mathrm{D}=$ crystallite size

$\beta=$ full width at half maximum intensity

$\theta=$ diffraction angle

$0.9=$ shape factor

Table 2: crystallite size and cell parameters obtained from XRD spectra

\begin{tabular}{|l|l|l|l|l|l|l|}
\hline compound & Miller indices & 20 degree & FWHM cm & D nm & $\begin{array}{c}\text { Cell parameters } \\
{ }^{\circ} \mathrm{A}\end{array}$ & $\begin{array}{c}\text { Cell volume } \\
{ }^{\circ} \mathrm{A}^{3}\end{array}$ \\
\hline A-TiO2 & 101 & 25.28 & 0.4324 & 18.62 & $\mathrm{a}=3.779 \mathrm{c}=9.665$ & 138.024 \\
\hline R-TiO2 & 110 & 27.43 & 0.2104 & 38.43 & $\mathrm{a}=4.549 \mathrm{c}=2.946$ & 62.174 \\
\hline T-K-600 & 101 & 25.40 & 0.4990 & 16.14 & $\mathrm{a}=3.761 \mathrm{c}=9.628$ & 136.189 \\
\hline T-K-850 & 110 & 27.58 & 0.2770 & 29.20 & $\mathrm{a}=4.570 \mathrm{c}=2.937$ & 61.338 \\
\hline T-Na-600 & 101 & 25.45 & 0.5212 & 15.45 & $\mathrm{a}=3.753 \mathrm{c}=9.621$ & 135.511 \\
\hline T-Na-850 & 110 & 27.63 & 0.2993 & 27.03 & $\mathrm{a}=4.562 \mathrm{c}=2.933$ & 61.041 \\
\hline
\end{tabular}

As shown in table(2), the cell parameters and cell volume of modified tio2 lower than that as-prepared tio2, also, we can note that the crystallite size of modified tio 2 smaller than that for reduced tio 2 which is derived from oxygen vacancies induced lattice strains and slightly reduced crystal size and lattice contraction $(24,25,26)$.
Moreover, the lattice contraction in case of T-Na-600 larger than that of T-K-600, similarly, the contraction in the T-Na- 850 is larger than $\mathrm{T}-\mathrm{K}-850$ this is because $\mathrm{NaAlH} 4$ represent a stronger reducing agent as compared with $\mathrm{KBH} 4$. 


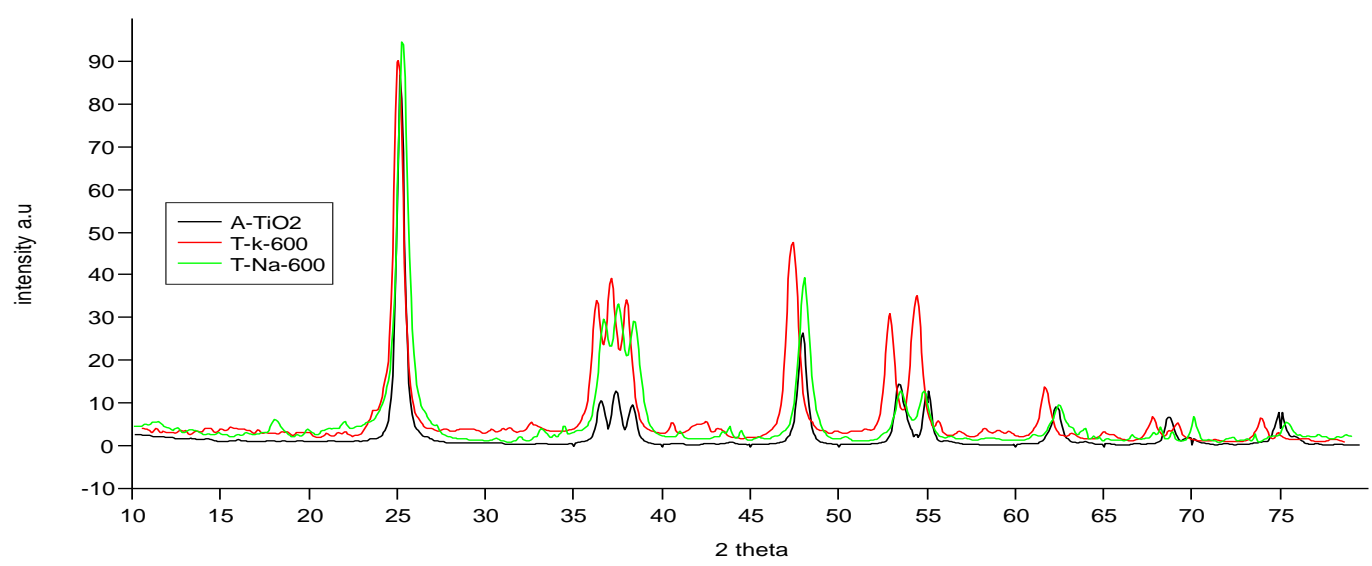

Figure 1 : xrd patterns of A-TiO2, T-K-600, T-Na-600

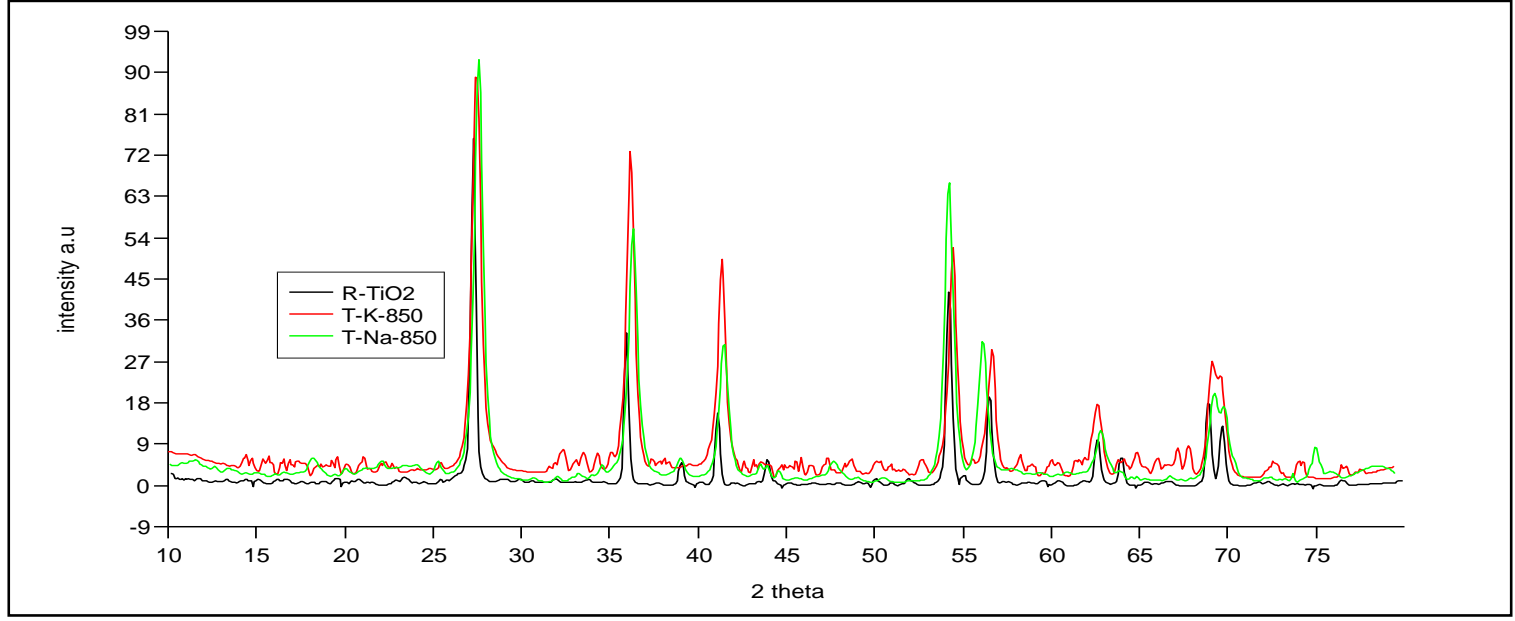

Figure 2 : xrd patterns of R-TiO2, T-K-850, T-Na-850

The optical properties of the $\mathrm{TiO} 2$ nanoparticles were characterized Using UV-vis spectroscopy, figure (3) illustrate the absorption spectra , One of the most successful methods for determining the bandgap energy is Tauc plot, The bandgap energy (Eg) can be calculated using the following equation(27):

$\alpha \mathrm{h} v=\mathrm{A}\left(\mathrm{h} v-\mathrm{E}_{\mathrm{g}}\right)^{1 / 2}$ by extrapolating the tangent line of the $(\alpha h v) 1 / 2$ plot drown vs. h $v$ we can obtain the Eg values of as-prepared and modified tio2. As shown in figure(4) and table (3), the band gap was approximately $3.2 \mathrm{ev}$ and $2.9 \mathrm{ev}$ for $\mathrm{A}-\mathrm{TiO} 2$ and $\mathrm{R}-\mathrm{TiO} 2$ respectively.

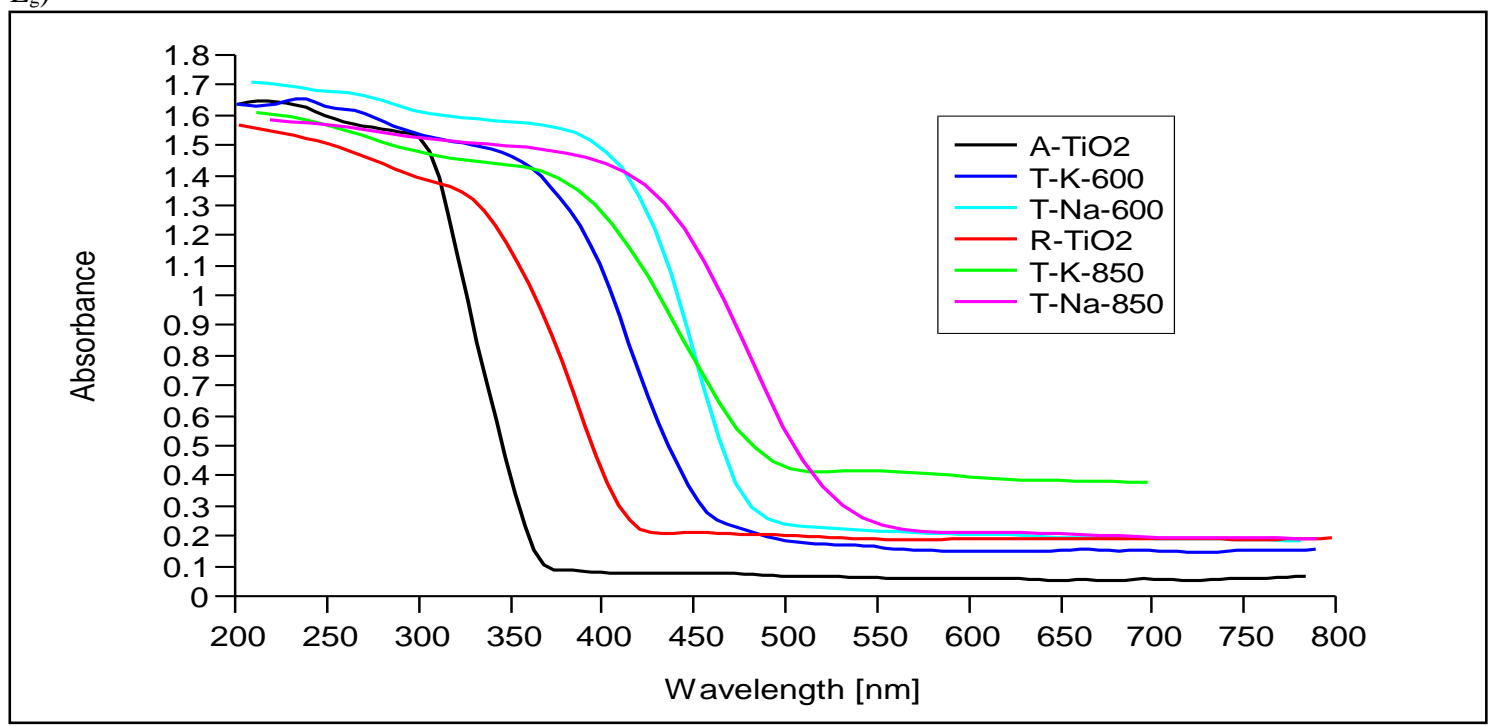

Figure 3 : UV-Vis spectra of prepared and modified $\mathrm{TiO} 2$ 


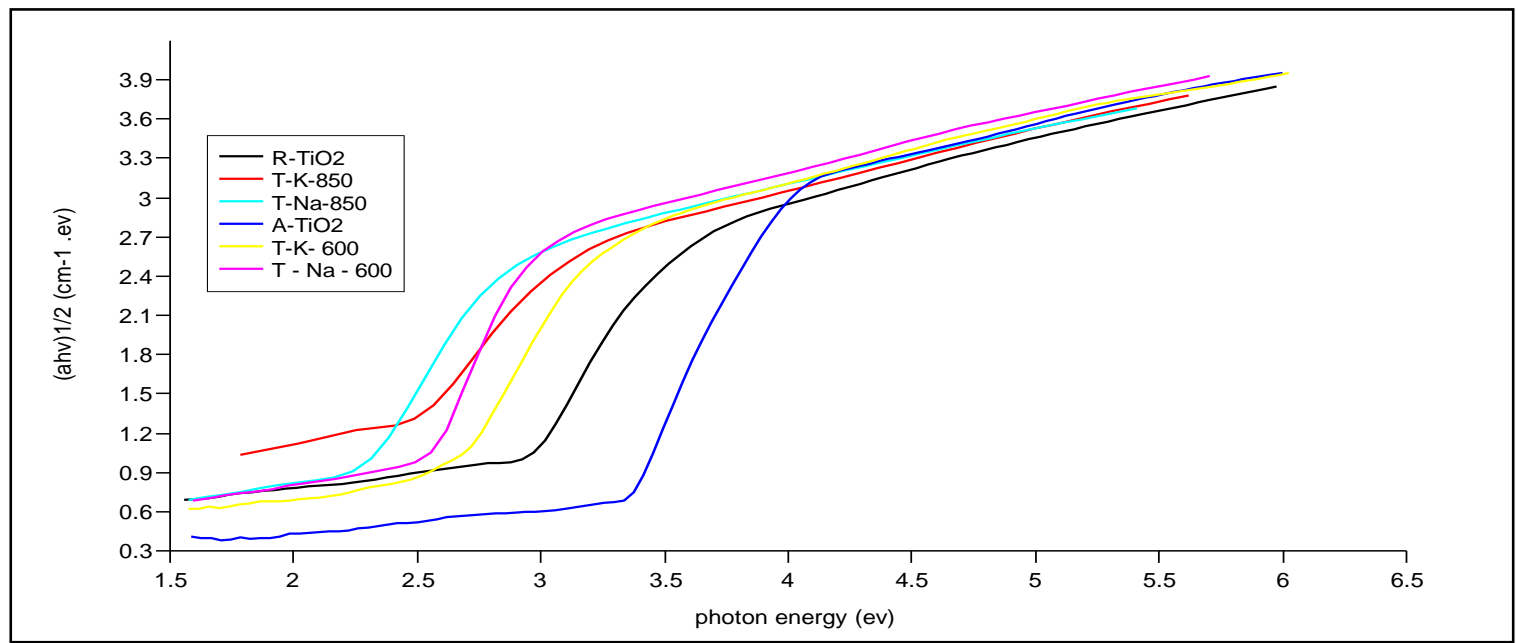

Fig. 4 : Tauc plot of as-prepared and modified $\mathrm{TiO} 2$

On the other hand, reduction treatment shift the absorption edge from the ultraviolet to visible region and the band gap become smaller, the band gap of T-Na-600, T-Na-850 more effected by reduction treatment and therefore have lower band gap. however, the introducing oxygen vacancies by reduction treatment generate local states below the conduction band edge and extend the light absorption of $\mathrm{TiO} 2$ nanoparticles from the UV to the visible region $(28,29)$.

Table 3: calculated band gap of prepared and modified tio2

\begin{tabular}{|l|l|}
\hline Sample & Energy gap (ev) \\
\hline A-TiO2 & 3.2 \\
\hline R-TiO2 & 2.78 \\
\hline T-K-600 & 2.43 \\
\hline T-Na-600 & 2.4 \\
\hline T-K-850 & 2.04 \\
\hline T-Na-850 & 2.02 \\
\hline
\end{tabular}

The nanoparticles grin size and the surface morphology of prepared and modified tio2 were analyzed by atomic force microscopy (AFM). figs.(5-7) show the AFM 2D images of prepared and modified tio 2 nanoparticles, we can note that the asprepare $\mathrm{TiO} 2$ nanoprticles has a uniform and smooth surface. Also, the grain size of modified $\mathrm{TiO} 2$ appears smaller than that asprepared tio 2 as shown in table 4, contrary, the surface roughness parameters of modified tio2 larger than that unmodified tio2, this can explained by the formation of oxygen vacancies (30).

Table 4 : roughness values and grain size of as-prepared and modified tio2

\begin{tabular}{|c|c|c|c|}
\hline compound & Surface roughness Ra nm & Root mean square RMS nm & $\begin{array}{c}\text { Grain size } \\
\text { nm }\end{array}$ \\
\hline R-TiO2 & & 1.117 & 114.8 \\
\hline A-TiO2 & 0.925 & 1.145 & 80.76 \\
\hline T-K-850 & 0.911 & 1.163 & 81.35 \\
\hline T-K-600 & 0.948 & 1.396 & 74.16 \\
\hline T-Na-850 & 1.073 & 1.979 & 81.22 \\
\hline T-Na-600 & 1.662 & 2.102 & 44.72 \\
\hline
\end{tabular}

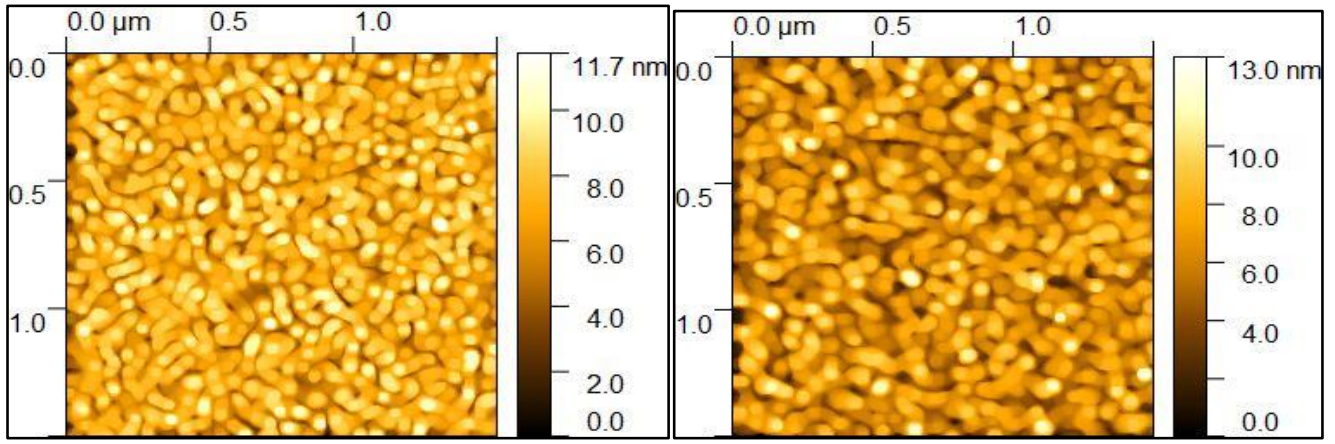

Figure $5: 1.5$ x 1.5um 2D AFM images of R-TiO2(left) and A-TiO2 (right) 


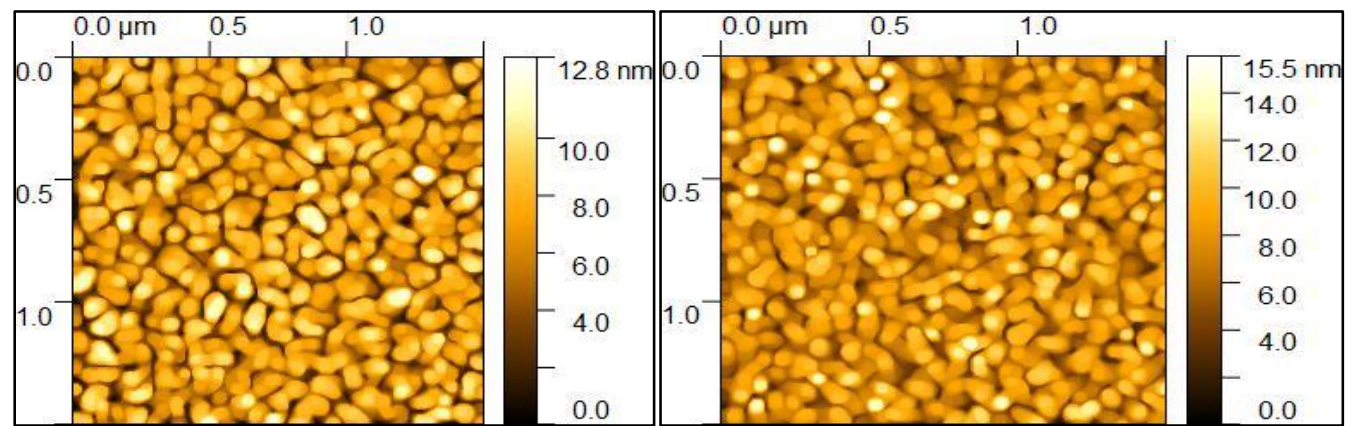

Figure $6: .5$ x 1.5um 2D AFM images of T-K-850(left) and T-K-600 (right)

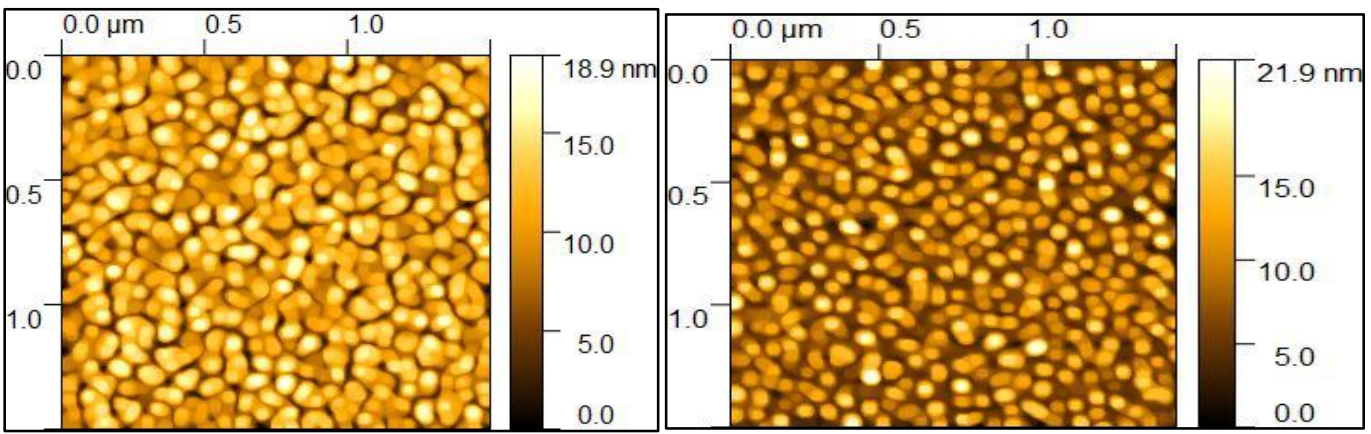

Figure 7: 1.5x1.5um 2D AFM images of T-Na-850(left) and T-Na-600 (right)

The elemental structure of as-prepared and modified $\mathrm{TiO} 2$ was done using

Energy Dispersive Spectroscopy (EDS), as shown in figs. (8-10), The Ti and $\mathrm{O}$ peaks can be found in all EDS spectra without any other peaks, this indicate that the as-prepared and modified $\mathrm{TiO} 2$ nanoparticles are pure and successfully removal of unreacted reducing agents after reduction treatment.

We can calculate the stoichiometry of all compounds from the atomic and weight percentage values(insets in figures 8-10), as we can note from table 5, the stoichiometry of as-prepared compounds match the standard chemical formula of $\mathrm{TiO}$, while the oxygen vacancies formation as a result of reduction treatment make the resulted compounds nonstoichiometry. Generally, EDS measurements confirms the formation of defective $\mathrm{TiO} 2$ nanoparticles after the reduction treatment which implying the presence of defective $\mathrm{TiO} 2-x$ layer surrounding the $\mathrm{TiO} 2$ core (31).

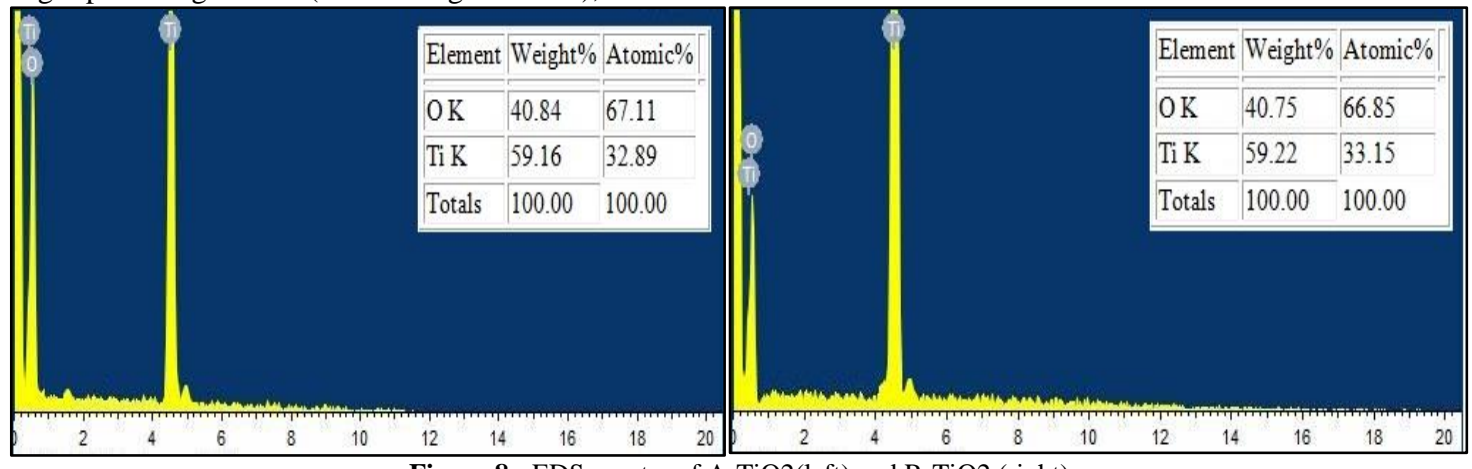

Figure 8 : EDS spectra of A-TiO2(left) and R-TiO2 (right)
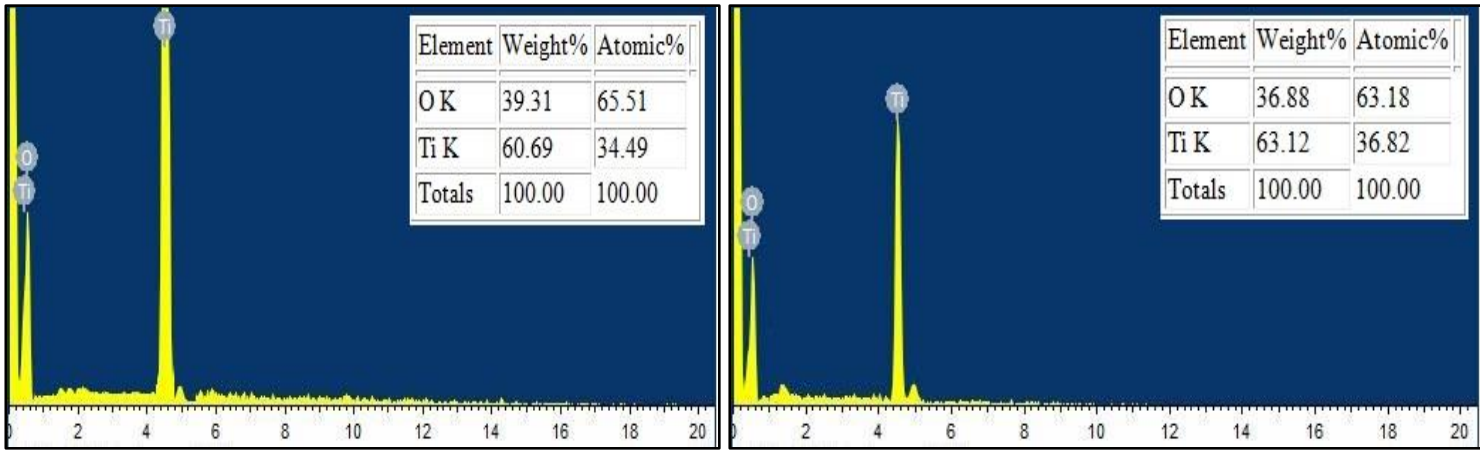

Figure 9 : EDS spectra of T-K-600(left) and T-K-850 (right) 

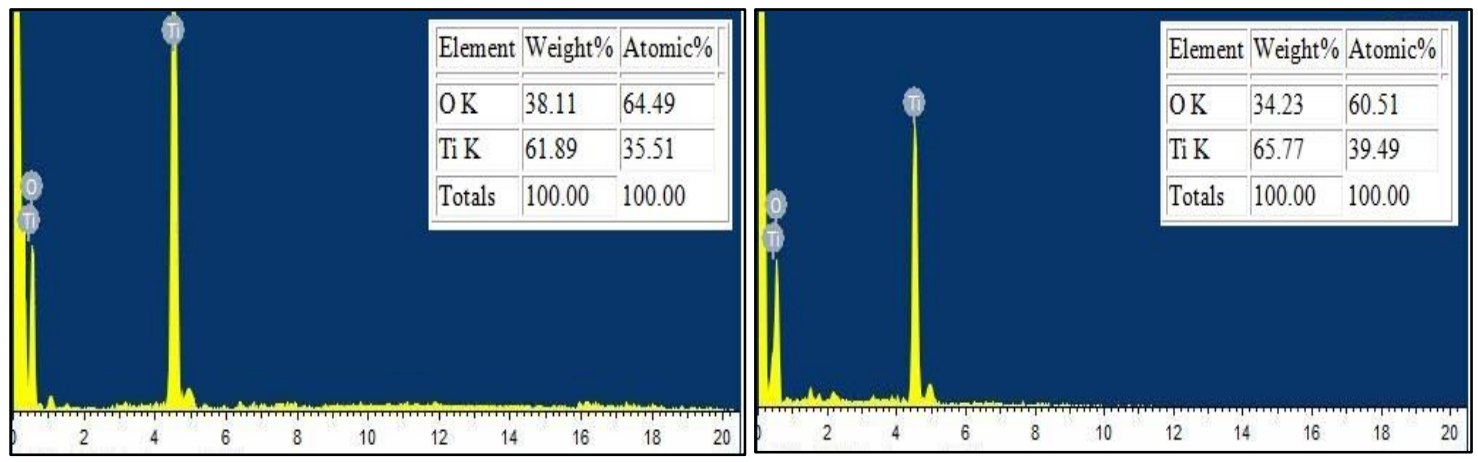

Figure 10 : EDS spectra of T-Na-600(left) and T-Na-850 (right)

Table 5 : calculated chemical formula

\begin{tabular}{|l|l|}
\hline Compound & Formula \\
\hline A-TiO2 & TiO2 \\
\hline R-TiO2 & TiO2 \\
\hline T-K-600 & TiO1.89 \\
\hline T-Na-600 & TiO1.81 \\
\hline T-K-850 & TiO1.71 \\
\hline T-Na-850 & TiO1.53 \\
\hline
\end{tabular}

\subsection{Computational details}

To obtain the relaxed structures, we used the SIESTA implementation of density functional theory (DFT) to optimise the structures using, LDA, the local density approximation with the Ceperley-Alder exchange correlation functional and, DZP, double zeta polarized basis set [241] The initial unit cells were relaxed until the forces on the atoms are minimised to below $0.01 \mathrm{eV} \AA^{-1}$. Results are obtained for the electronic density of states (DOS).

\subsection{Oxygen vacancies in anatase $\mathrm{TiO} 2$}

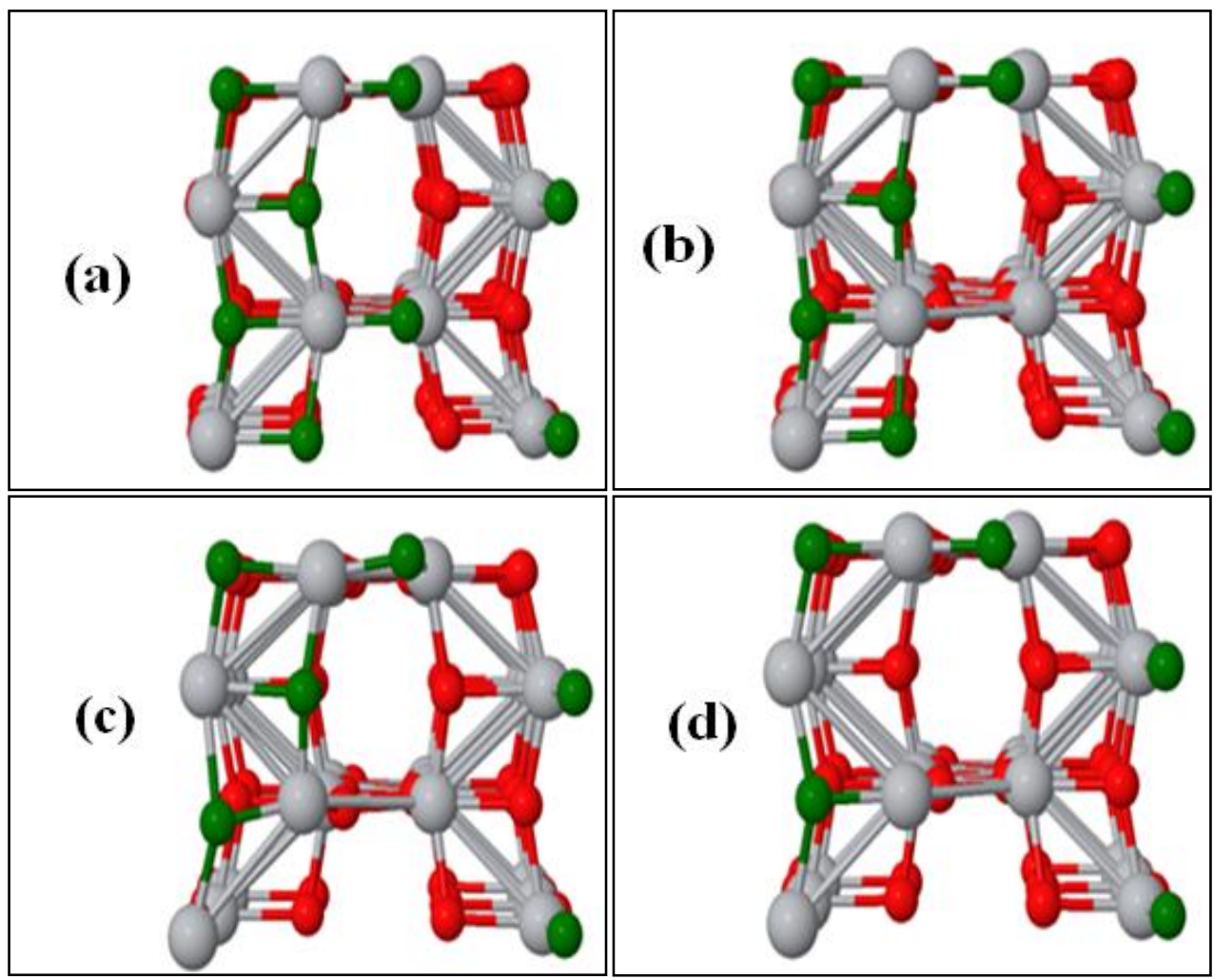

Figure (11) Relaxed structure geometries of (a): anatase $\mathrm{TiO}_{2},(\mathrm{~b}-\mathrm{d})$ : $\mathrm{TiO}_{2}$ anatase with one, two and there oxygen vacancies respectively. Large gray sphere and small red sphere represent $\mathrm{Ti}$ and $\mathrm{O}$ atoms reactively, green colour sphere denoted to $\mathrm{O}$ surface atoms.
To examine the effect of oxygen vacancies in anatase $\mathrm{TiO}_{2}$, we relax a super unit cell of ideal $\mathrm{TiO}_{2}$ which contains 72 atoms (48 oxygen atoms and 24 titanium atoms) to obtain the relaxed structure, then we calculate the density of states, DOS. Later we simulate three different super unit cells; first we remove one oxygen atom from the unrelaxed super unit cell (71 atoms) and then optimize it, second we remove two oxygen atoms from the initial super unit cell (70 atoms) and relax it, and finally we remove three oxygen atoms from the initial super cell (69 atoms) and relax it. For all the three different unit cells, we calculate the density of states. 


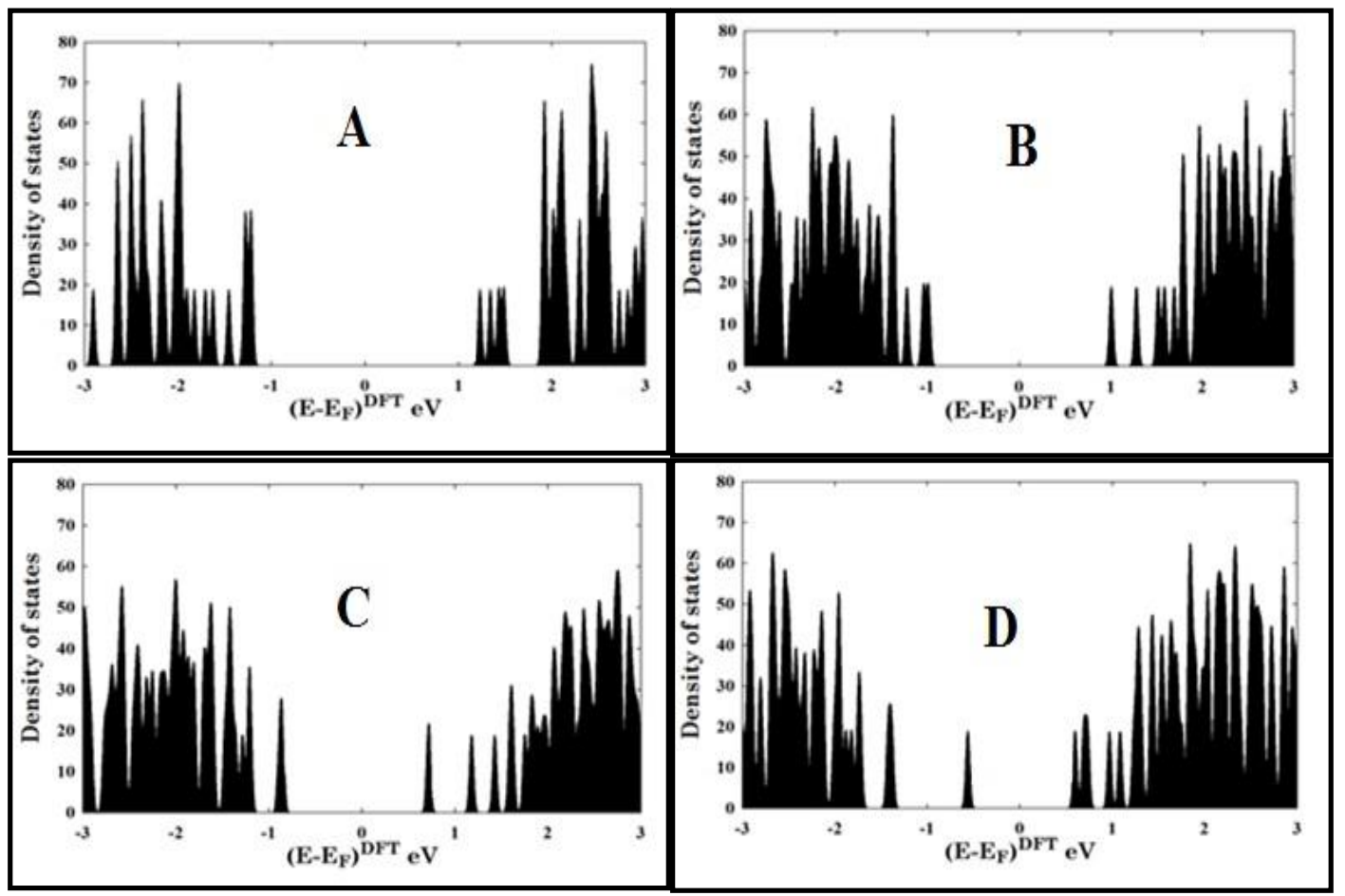

Figure (12) DOS of (a): anatase $\mathrm{TiO}_{2}$, (b-d): $\mathrm{TiO}_{2}$ anatase with one, two and there oxygen vacancies respectively.

\subsection{Oxygen vacancies in rutile $\mathrm{TiO}_{2}$}

To examine the effect of oxygen vacancies in rutile $\mathrm{TiO}_{2}$, we relax a super unit cell of ideal $\mathrm{TiO}_{2}$ which contains 24 atoms ( 16 oxygen atoms and 8 titanium atoms) then we repeat the same strategy that used in case of anatase $\mathrm{TiO}_{2}$ by removing one, two and three oxygen atoms from the initial unit cells.

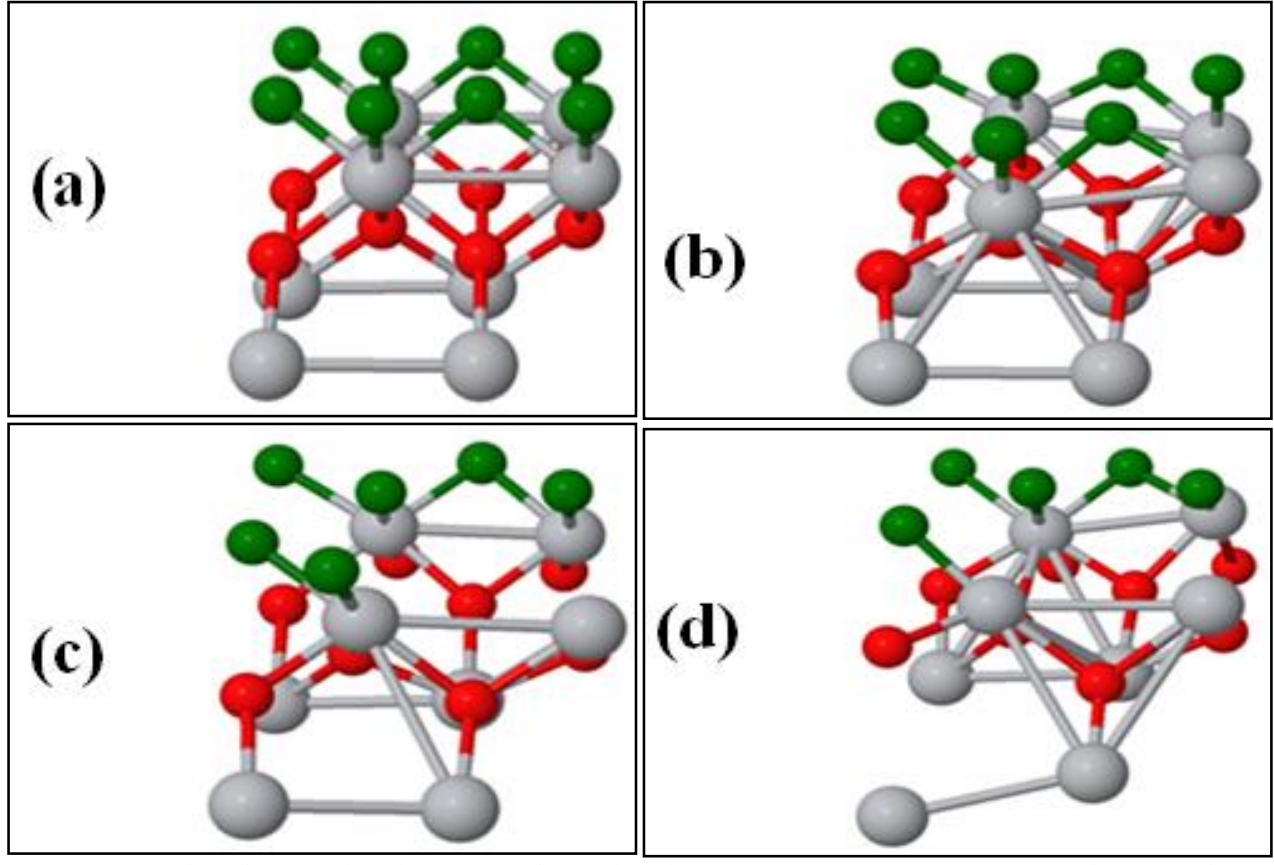

Figure (13) Relaxed structure geometries of (a): Rutile $\mathrm{TiO}_{2},(\mathrm{~b}-\mathrm{d})$ : $\mathrm{TiO}_{2}$ rutile with one, two and there oxygen vacancies respectively. Large gray sphere and small red sphere represent $\mathrm{Ti}$ and $\mathrm{O}$ atoms reactively, green colour sphere denoted to $\mathrm{O}$ surface atoms. 


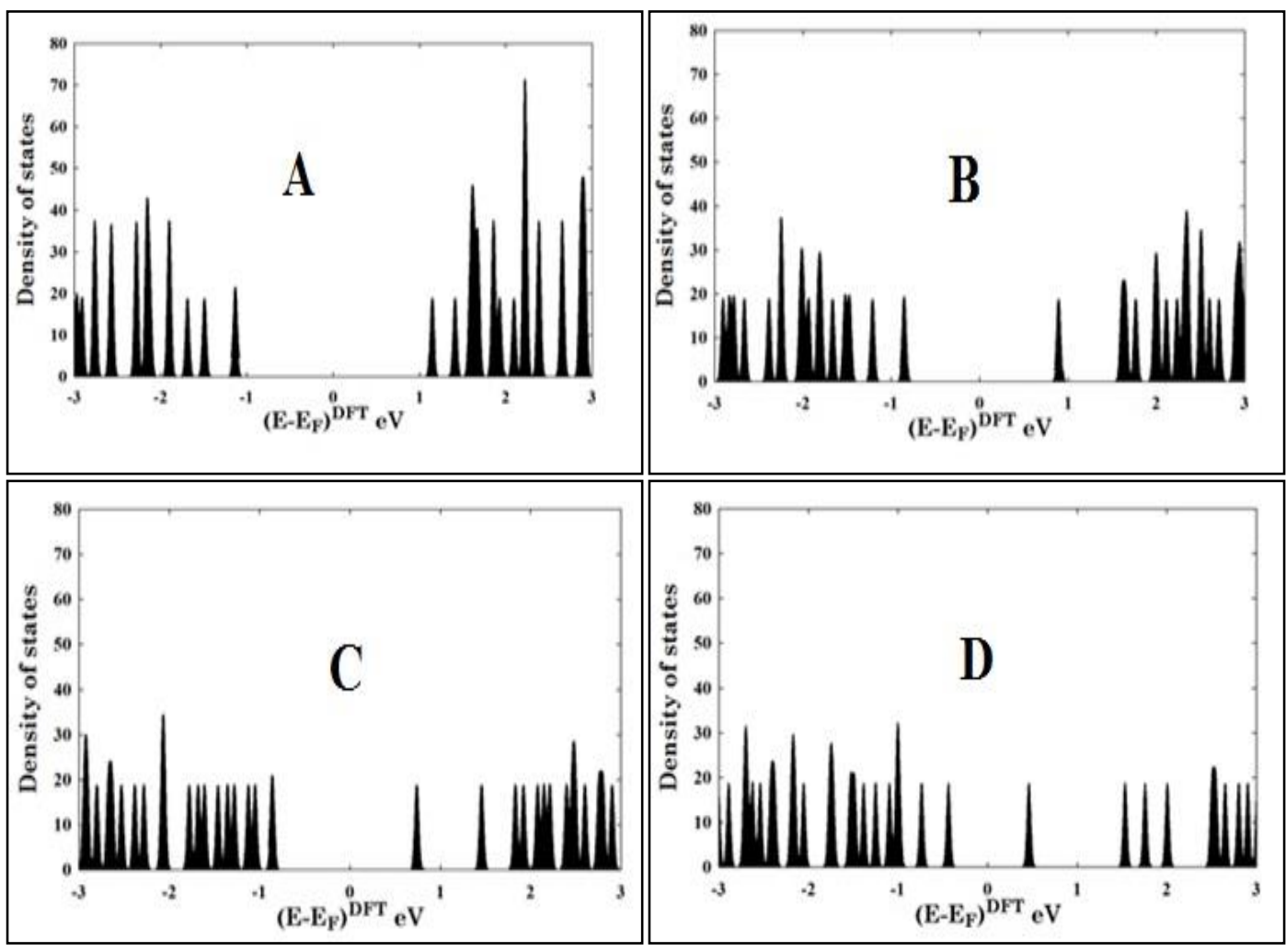

Figure (14) DOS of (a): Rutile $\mathrm{TiO}_{2}$, (b-d): $\mathrm{TiO}_{2}$ rutile with one, two and there oxygen vacancies respectively.

\subsection{Electronic properties:}

Due to the importance of anatase and rutile $\mathrm{TiO}_{2}$ energy gap for different applications, the (Eg) of pristine and reduced $\mathrm{TiO}_{2}$ were extracted from DOS plots figures (12) and (14) and the results are summarized in table (6). The results shows that the calculated energy gap of pristine anatase and rutile $\mathrm{TiO} 2$ is about 2.65 and $2.28 \mathrm{eV}$ respectively, which is underestimated by approximately one third comparing with the experimental values of 3.2 and 2.78 $\mathrm{eV}$ for anatase and rutile respectively. This remarkable discrepancy between experimental and theoretical studies can be observed due to the known limitation of the DFT theory. Many publications reported that the DFT theory calculation lowered the energy by about $30 \%$ compared with the experimental value [242-247].

As the number of removed oxygen atoms increase, the energy gap values deeply decreased, hence removing three oxygen atoms from the structures lead to remarkably reduce in the energy gap from $2.65 \mathrm{eV}$ to $1.161 \mathrm{eV}$ and from $2.28 \mathrm{eV}$ to $0.747 \mathrm{eV}$ for anatase and rutile $\mathrm{TiO}_{2}$ respectively.

Table (6): Calculated energy gaps (eV) for all $\mathrm{TiO}_{2}$ structures

\begin{tabular}{|l|l|l|l|l|}
\hline \multirow{2}{*}{ Oxygen removed } & \multicolumn{4}{|c|}{$\mathrm{Eg}(\mathrm{eV})$} \\
\cline { 2 - 6 } & Pristine & $1 \mathrm{O}$ & $2 \mathrm{O}$ & $3 \mathrm{O}$ \\
\hline Anatase & 2.650 & 1.996 & 1.571 & 1.161 \\
\hline Rutile & 2.280 & 1.672 & 1.328 & 0.747 \\
\hline
\end{tabular}

However, the decrease in the energy gap can be explained by the formation of oxygen vacancies, the results of DOS (figures 12 and 14) indicate that the vacancy band created below the conduction band minimum (CBM) as a result of the formation of oxygen vacancy. As the oxygen vacancy concentration increase, the vacancy band shifts deeper below the CBM [248].

According to the above theoretical results, we can conclude that the structures with two oxygen vacancies are closed to our experimental study for reduced $\mathrm{TiO}_{2}$ taking into account the previously mentioned DFT limitation.

\section{Conclusions}

In this work, reduced $\mathrm{TiO} 2$ nanoparticles were synthesized using sold state reaction of as-prepared $\mathrm{TiO} 2$ with $\mathrm{NaAlH} 4$ and $\mathrm{KBH} 4$ as a reducing agents. The structural properties analyzed by XRD show a slightly difference from the as-prepared $\mathrm{TiO} 2$ but have the same antase and rutile phases, the line broadening and larger diffraction angles of reduced $\mathrm{TiO} 2$ related to the formation of oxygen vacancies. The results of morphology analysis indicate that the reduced $\mathrm{TiO} 2$ have a surface roughness larger than of as-prepared $\mathrm{TiO} 2$ and the grain size decreased after reduction treatment. The purity of prepared and reduced $\mathrm{TiO} 2$ confirmed by EDS analysis and only $\mathrm{Ti}$ and $\mathrm{O}$ founded in the spectra, the stoichiometry calculations indicate formation $\mathrm{TiO} 2$ with oxygen deficient which also indicate formation oxygen vacancies in resulted oxide. Band gap measurement improves that the reduction treatment shifts the absorption spectra of reduced $\mathrm{TiO} 2$ from ultraviolet to the visible light region. 


\section{References}

[1] J. Yu, J. Low, W. Xiao, P. Zhou, M. Jaroniec, Enhanced photocatalytic CO2-reduction activity of anatase TiO2by coexposed $\left\{\begin{array}{lll}0 & 0 & 1\end{array}\right\}$ and $\begin{cases}1 & 0\end{cases}$ 1 \} facets,J. Am. Chem. Soc. 136 (2014) pp.8839-8842.

[2] A.A. Ashkarran, H. Hamidinezhad, H. Haddadi, M. Mahmoudi, Double-dopedTiO2nanoparticles as an efficient visible-light-active photocatalyst andantibacterial agent under solar simulated light, App. Surf. Sci. 301 (2014) pp.338-345.

[3] J. Tian, Z. Zhao, A. Kumar, R.I. Boughton, H. Liu, Recent progress in design, synthesis, and applications of one-dimensional TiO2nanostructured surfaceheterostructures: a review, Chem. Soc. Rev. 43 (2014) pp.6920-6937.

[4] A. Testino, I. R. Bellobono, V. Buscaglia, C. Canevali,M. D'Arienzo, S. Polizzi, R. Scotti and F. Morazzoni, Optimizing the photocatalytic properties of hydrothermal $\mathrm{TiO} 2$ by the control of phase composition and particle morphology. a systematic approach., J. Am.Chem. Soc., (2007),pp.129, 3564.

[5] J. Su, X. Zou, G.-D. Li, Y.-M. Jiang, Y. Cao, J. Zhao and J.-S. Chen, Room-temperature spontaneous crystallization of porous amorphous titania into a high-surface-area anatase photocatalyst., Chem. Commun., (2013), pp.49, 8217.

[6] J. Pan, G. Liu, G. Q. Lu and H. M. Cheng, On the True Photoreactivity Order of $\{001\},\{010\}$, and $\{101\}$ Facets of Anatase $\mathrm{TiO}_{2}$ Crystals, Angew. Chem., Int.Ed., (2011),pp. 50, 2133.

[7] X. Zou, R. Silva, X. Huang, J. F. Al-Sharab and T. Asefa, A self cleaning porous $\mathrm{TiO} 2-\mathrm{Ag}$ core-shell nanocomposite material for surface enhanced Raman scattering, Chem. Commun., (2013),pp. 49, 382.

[8] H. G. Yang, C. H. Sun, S. Z. Qiao, J. Zou, G. Liu, S. C. Smith,H. M. Cheng and G. Q. Lu, Anatase $\mathrm{TiO}_{2}$ single crystals with a large percentage of reactive facets ,Nature, (2008),pp.453, 638.

[9] L. Wang, T. Sasaki, Titanium oxide nanosheets: graphene analogues withversatile functionalities, Chem. Rev. 114 (2014) pp.9455-9486.

[10] Y. Wang, J. Yu, W. Xiao, Q. Li, Microwave-assisted hydrothermal synthesis of graphene based $\mathrm{Au}-\mathrm{TiO} 2$ photocatalysts for efficient visible-light hydrogen production, J. Mater. Chem. A 2 (2014) pp.3847-3855.

[11] R. Sasikala, A. Shirole, V. Sudarsan, T. Sakuntala, C. Sudakar, R. Naik, Highly dispersed phase of $\mathrm{SnO} 2$ on $\mathrm{TiO} 2$ nanoparticles synthesized by polyol-mediated route: Photocatalytic activity for hydrogen generation Int. J. Hydrogen Energy 34, (2009) pp.3621-3630.

[12] D. C. Cronemeyer, Infrared Absorption of Reduced Rutile TiO2 Single Crystals, Phys. ReV. 113(1959) 1222.

[13] Designed Self-Doped Titanium Oxide Thin Films for Efficient VisibleLight Photocatalysis, I. Justicia, P. Ordejon, G. Canto, J. L. Mozos, J. Fraxedes, G. A. Battiston, R. Gerbasi, A. Figueras, AdV. Mater. (2002) pp. 14,1399

[14] F. Zuo, L. Wang, T. Wu, Z. Zhang, D. Borchardt, P. Feng, Self-Doped Ti3+ Enhanced Photocatalyst for Hydrogen Production under ,J. Am. Chem. Soc. 132(2010) pp.11856-11857

[15] Z. Zheng, B. Huang, X. Meng, J. Wang, S. Wang, Z. Lou,Z. Wang, X. Qin, X. Zhang and Y. Dai, Metallic zinc-assisted synthesis of Ti 3+ self doped TiO 2 with tunable phase composition and visible-light photocatalytic activity, Chem. Commun., (2013) pp.49, 868 .

[16] F. N. Sayed, O. D. Jayakumar, R. M. Kadam, S. R. Bharadwaj,L. Kienle, U. Sch"urmann, S. Kaps, R. Adelung, J. P. Mittal andA. K. Tyagi, Photochemical Hydrogen Generation Using Nitrogen-Doped TiO2-Pd Nanoparticles: Facile Synthesis and Effect of Ti3+ Incorporation, J. Phys. Chem. C, (2012) pp.116, 12462.

[17] C. Yang, Z. Wang, T. Lin, H. Yin, X. Lu, D. Wang, T. Xu, C. Zheng, J. Lin, F. Huang, X. Xie and M. Jiang, Core-shell nanostructured "black" rutile titania as excellent catalyst for hydrogen production enhanced by sulfur doping, J. Am.Chem. Soc., (2013) pp.135, 17831.

[18] Q. Kang, J. Cao, Y. Zhang, L. Liu, H. Xu and J. Ye, Reduced $\mathrm{TiO}_{2}$ nanotube arrays for photoelectrochemical water splitting, J. Mater.Chem. A, (2013) pp. 1, 5766.

[19] X. Zou, J. Liu, J. Su, F. Zuo, J. Chen and P. Feng, Facile Synthesis of Thermal- and Photostable Titania with Paramagnetic Oxygen Vacancies for Visible-Light Photocatalysis ,Chem. - Eur.J., (2013) pp.19, 2866.
[20] F. Zuo, L. Wang, T. Wu, Z. Zhang, D. Borchardt and P. Feng, Self Doped $\mathrm{Ti}^{3+}$ Enhanced Photocatalyst for Hydrogen Production under Visible Light,J. Am. Chem. Soc., (2010) pp.132, 11856.

[21] N. Liu, V. Haublein, X. Zhou, U. Venkatesan, M. Hartmann, M. Mackovic,T. Nakajima, E. Spiecker, A. Osvet, L. Frey, P. Schmuki, "Black" TiO2 nanotubes formed by high-energy proton implantation show Noble-metal-co-catalyst free photocatalytic H2-evolution, Nano Lett. 15 (2015) pp. 6815-6820.

[22] S.G. Ullattil, P. Periyat, A 'one pot' gel combustion strategy towards Ti3+ self-doped 'black' anatase TiO2 - x solar photocatalyst, J. Mater. Chem. A 4 (2016) pp.5854-5858.

[23] J.H. Pan, Z.Y. Cai, Y. Yu, X.S. Zhao, Controllable synthesis of mesoporous F-TiO2 spheres for effective photocatalysis, J. Mater. Chem. 21(2011) pp. 11430.

[24] X. Chen, L. Liu, Z. Liu, M. A. Marcus, W. Wang, N. A. Oyler, M. E. Grass, B. Mao, P. Glans, P. Y. Yu, J. Guo, S. S. Mao, Properties of Disorder-Engineered Black Titanium Dioxide Nanoparticles through Hydrogenation, Scientific Reports,3(2013) pp.1510.

[25] W. Wang, Y. Ni, C. Lu and Z. Xu, hydrogenation of TiO2 nanosheets with exposed $\{001\}$ facets for enhanced photocatalytc activity, RSC Adv., 2(2012) pp. 8286.

[26] Z. Wang, C. Yang, T. Lin, H. Yin, P. Chen, D. Wan, F. Xu, F. Huang J. Lin, X. Xiec, M. Jiangc, Visible-light photocatalytic, solar thermal and photoelectrochemical properties of aluminium-reduced black titania, Energy Environ. Sci., 6(2013) pp. 3007.

[27] Y. Jiang, F. Li, Y. Liu, Y. Hong, P. Liu, L. Ni, Construction of TiO2 hollow nanosphere/g -C3N4 composites with 2 superior visible-light photocatalytic activity and mechanism insight, Ind. Eng. Chem. Res. 41(2016) pp.130-141.

[28] X.Y. Pan, M.-Q. Yang, X.Z. Fu, N. Zhang, Y.-J. Xu, Defective TiO2 with oxygen vacancies: synthesis, properties and photocatalytic applications, Nanoscale, 5 (2013) pp.3601-3614.

[29] B. Bharti, S. Kumar, H.-N. Lee and R. Kumar, Formation of oxygen vacancies and $\mathrm{Ti} 3+$ state in $\mathrm{TiO} 2$ thin $\mathrm{lm}$ and enhanced optical properties by air plasma treatment, Sci. Rep.,6 (2016) pp.32355.

[30] V. Gurylev, C.Y. Su and T.P. Perng, Surface reconstruction, oxygen vacancy distribution and photocatalytic activity of hydrogenated titanium oxide thin film, Journal of Catalysis, 330 (2015) pp.177-186.

[31] M. W. Shah, Y. Zhu, X. Fan, J. Zhao, Y. Li, S. Asim, C. Wang, Facile Synthesis of Defective TiO2- $x$ Nanocrystals with High Surface Area and Tailoring Bandgap for Visible-light Photocatalysis, Scientific reports 5, (2015) pp.15804.

[32] Soler, J. M., Artacho, E., Gale, J. D., García, A., Junquera, J., Ordejón, P., \& Sánchez-Portal, D. The SIESTA method for ab initio order-N materials simulation. Journal of Physics: Condensed Matter, 14,11 (2002) pp.2745.

[33] Yang, K., Dai, Y., \& Huang, B. Study of the nitrogen concentration influence on $\mathrm{N}$-doped $\mathrm{TiO} 2$ anatase from first-principles calculations. The journal of physical chemistry C, 111(32). (2007). pp.12086-12090.

[34] Wan, L., Li, J. F., Feng, J. Y., Sun, W., \& Mao, Z. Q. Anatase TiO2 films with $2.2 \mathrm{eV}$ band gap prepared by micro-arc oxidation. Materials science and engineering: B, 139(2-3), (2007) pp.216-220.

[35] Zhang, Y. F., Lin, W., Li, Y., Ding, K. N., \& Li, J. Q. A Theoretical Study on the Electronic Structures of TiO2: Effect of Hartree- Fock Exchange. The Journal of Physical Chemistry B, 109,41 (2005) pp.19270-19277.

[36] Glassford, K. M., \& Chelikowsky, J. R. Structural and electronic properties of titanium dioxide. Physical Review B, 46,3 (1992) pp.1284.

[37] Yang, K., Dai, Y., Huang, B., \& Whangbo, M. H. Density functional characterization of the band edges, the band gap states, and the preferred doping sites of halogen-doped TiO2. Chemistry of Materials, 20,20 (2008) pp.6528-6534.

[38] Su, R., Tiruvalam, R., He, Q., Dimitratos, N., Kesavan, L., Hammond, C., ... \& Besenbacher, F. Promotion of phenol photodecomposition over $\mathrm{TiO} 2$ using $\mathrm{Au}, \mathrm{Pd}$, and $\mathrm{Au}-\mathrm{Pd}$ nanoparticles. ACS nano, 6,7 (2012) pp.6284-6292.

[39] Janotti, A., Varley, J. B., Rinke, P., Umezawa, N., Kresse, G., \& Van de Walle, C. G. Hybrid functional studies of the oxygen vacancy in TiO 2. Physical Review B, 81,8 (2010) pp.085212. 